This is the author's final, peer-reviewed manuscript as accepted for publication. The publisher-formatted version may be available through the publisher's web site or your institution's library.

\title{
Role of anthocyanin-enriched purple-fleshed sweet potato p40 in colorectal cancer prevention
}

Soyoung Lim, Jianteng Xu, Jaeyong Kim, Tzu-Yu Chen, Xiaoyu Su, Joseph Standard, Edward Carey, Jason Griffin, Betty Herndon, Benjamin Katz, John Tomich, Weiqun Wang

\section{How to cite this manuscript}

If you make reference to this version of the manuscript, use the following information:

Lim, S., Xu, J., Kim, J., Chen, T.-Y., Su, X., Standard, J., ... Wang, W. (2013). Role of anthocyanin-enriched purple-fleshed sweet potato p40 in colorectal cancer prevention. Retrieved from http://krex.ksu.edu

\section{Published Version Information}

Citation: Lim, S., Xu, J., Kim, J., Chen, T.-Y., Su, X., Standard, J., ... Wang, W. (2013). Role of anthocyanin-enriched purple-fleshed sweet potato p40 in colorectal cancer prevention. Molecular Nutrition \& Food Research, 57(11), 1908-1917.

Copyright: (c) 2013 WILEY-VCH Verlag GmbH \& Co.

Digital Object Identifier (DOI): doi:10.1002/mnfr.201300040

Publisher's Link: http://onlinelibrary.wiley.com/doi/10.1002/mnfr.201300040/full

This item was retrieved from the K-State Research Exchange (K-REx), the institutional repository of Kansas State University. K-REx is available at http://krex.ksu.edu 
Role of Anthocyanin-enriched Purple-fleshed Sweet Potato P40 in Colorectal Cancer

Prevention

Soyoung $\mathrm{Lim}^{1}$, Jianteng $\mathrm{Xu}^{1}$, Jaeyong Kim${ }^{1}$, Tzu-Yu Chen ${ }^{1}$, Xiaoyu $\mathrm{Su}^{1}$, Joseph Standard ${ }^{1}$, Edward Carey ${ }^{2}$, Jason Griffin ${ }^{3}$, Betty Herndon ${ }^{4}$, Benjamin Katz ${ }^{5}$, John Tomich ${ }^{5}$, Weiqun Wang ${ }^{1}$

${ }^{1}$ Department of Human Nutrition, Kansas State University, Manhattan, KS, USA

${ }^{2}$ International Potato Center, Kumasi, Ghana

${ }^{3}$ Department of Horticulture, Kansas State University, Manhattan, KS, USA

${ }^{4}$ School of Medicine, University of Missouri-Kansas City, Kansas City, MO, USA

${ }^{5}$ Department of Biochemistry, Kansas State University, Manhattan, KS, USA

Correspondence: Professor Weiqun Wang, Department of Human Nutrition, Kansas State University, Manhattan, KS 66506, USA

e-mail: wwang@ksu.edu

Fax: +1-785-532-3132

Abbreviations: AOM, azoxymethane; ACF, aberrant crypt foci; PCNA, proliferating cell nuclear antigen; P3G, peonidin 3-glucoside; P3GE, peonidin 3-glucoside equivalent; GAE, gallic acid equivalent; TE, trolox equivalent. 
Scope: Anthocyanins, the natural pigments in plant foods, have been associated with cancer prevention. However, the content of anthocyanins in staple foods is typically low and the mechanisms by which they exert anti-cancer activity is not yet fully defined.

Methods and results: We selected an anthocyanin-enriched purple-fleshed sweet potato clone, $\mathrm{P} 40$, and investigated its potential anti-cancer effect in both in vitro cell culture and in vivo animal model. In addition to a high level of total phenolics and antioxidant capacity, P40 possesses a high content of anthocyanins at $7.5 \mathrm{mg} / \mathrm{g}$ dry matter. Treatment of human colonic SW480 cancer cells with P40 anthocyanin extracts at $0-40 \mu \mathrm{M}$ of peonidin-3-glucoside equivalent resulted in a dose-dependent decrease in cell number due to cytostatic arrest of cell cycle at G1 phase but not cytotoxicity. Furthermore, dietary P40 at 10-30\% significantly suppressed azoxymethane-induced formation of aberrant crypt foci in the colons of CF-1 mice in conjunction with, at least in part, a lesser proliferative PCNA and a greater apoptotic caspase-3 expression in the colon mucosal epithelial cells.

Conclusion: These observations, coupled with both in vitro and in vivo studies reported here, suggest anthocyanin-enriched sweet potato P40 may protect against colorectal cancer by inducing cell cycle arrest, anti-proliferative and apoptotic mechanisms.

Keywords: Anthocyanins / Purple-fleshed sweet potato / SW480 colon cancer cells / Aberrant crypt foci / Mice / Colorectal cancer prevention

\section{Introduction}

Sweet potato (Ipomoea batatas [L.] Lam.), the sixth crop worldwide in terms of production, is widely cultivated and consumed in Sub-Saharan Africa, East Asia, and Oceania. A major 
advantage of sweet potato is its ability to grow in various climates and different farming systems. In addition to its value as a staple food, sweet potatoes contain many phytochemicals that may provide special health benefits [1]. For example, white-fleshed purple skin sweet potatoes contain high contents of beta-carotene and are being used to effectively combat vitamin Adeficiency in Mozambique and Uganda [2, 3]. Purple-fleshed sweet potato is enriched with anthocyanins. Anthocyanins are phenolic compounds responsible for the intense color of many fruits and vegetables such as red grapes, berries, red cabbages and purple sweet potatoes [4].

In addition to use as food colorants, anthocyanins have demonstrated nutraceutical functions [5]. Due to a naturally occurring high levels detected, berry anthocyanins have been extensively studied. It has been found that berry anthocyanins may prevent multiple chronic diseases such as cardiovascular disease [6], diabetes [7], cancer [8], and age-related neurodegenerative decline [9]. Studies conducted in animal models demonstrated that dietary berry anthocyanins might protect against carcinogen azoxymethane (AOM)-induced colon carcinogenesis $[10,11]$. The potential mechanisms by which berry anthocyanins may prevent colorectal cancer may relate to apoptosis induction and cell cycle arrest as well as inhibition of proliferation, inflammation, and angiogenesis [12-14].

In contrast to berries, sweet potatoes belong to staple foods. Purple-fleshed sweet potatoes also contain a high content of anthocyanins. However, it should be noted that anthocyanins in sweet potatoes are generally acylated and thus are different from the berry anthocyanins. The effects of the unique anthocyanins in the purple-fleshed sweet potato on colorectal cancer prevention and the underlying mechanisms are largely unknown. In this study, we selected a new variety of purple-fleshed sweet potato, clone P40, from a population of seeds 
obtained from the International Potato Center in Lima, Peru. In addition to a high content of total phenolics and antioxidant capacity, P40 possesses a high content of anthocyanins. We hypothesized that anthocyanin-enriched P40 may provide a pronounced anti-cancer ability. To test this hypothesis, two studies were performed: the impact of P40 anthocyanin extracts in an in vitro colonic cancer cell culture, and an in vivo dietary P40 in AOM-induced aberrant crypt foci in the colons of a murine model, were elucidated. Potential mechanism-related targets were examined in this study. Better understanding of the anti-cancer activity of P40 and the underlying anti-cancer mechanisms broadens appreciation for use of foods in cancer prevention, particularly a staple food such as the sweet potato studied here.

\section{$2 \quad$ Materials and methods}

\subsection{Reagents}

All HPLC-grade organic solvents used in this study were purchased from Thermo Fisher Scientific (Pittsburgh, PA, USA). A kit for total dietary fiber assay was provided by Megazyme International (Wicklow, Ireland). Folin-Ciocalteu reagent, gallic acid, 2,4,6-tri-2-pyridyl-striatine (TPTZ), $\mathrm{FeCl}_{3}$ trolox, Celite, Dulbecco's Modified Eagle medium, fetal bovine serum, penicillin/streptomycin, trypsin-EDTA, trypan blue, propidium iodide (PI), RNase, azoxymethane (AOM, 98\% pure), 10\% neutral buffered formalin, methylene blue, and rabbit anti-caspase 3 were obtained from Sigma-Aldrich (St. Louis, MO, USA). PCNA staining kit was purchased from Invitrogen (Carlsbad, CA, USA). Secondary label donkey anti-rabbit HRP was offered by Santa Cruz Biotechnology (Santa Cruz, CA, USA). Peonidin-3-glucoside chloride was obtained from Chromadex (Irvine, CA, USA). Human colon cancer line, SW480 was acquired from ATCC (Manassas, VA, USA). Female CF-1 mice were supplied by Charles River 
(Wilmington, MA, USA). AIN-93M powdered diet was purchased from Harlan (Indianapolis, IN, USA).

Sweet potato germplasm was maintained and grown at the Kansas State University John C. Pair Horticulture Research Center, Wichita, Kansas. Purple-fleshed sweet potatoes were initially bred using crossbred seeds obtained from the International Potato Center in Lima, Peru. Over 2000 seedlings from four full-sib progenies were cultured, evaluated, and selected in the field. One genotype, designated as P40, exhibited intense anthocyanin pigmentation and reasonable yield, was selected for comparison with the classic cream-fleshed O'Henry and white-fleshed purple skin NC Japanese cultivars as the controls in this study (Figure 1).

\subsection{Sweet potato samples and anthocyanin extraction}

For each of the sweet potato samples, tubers were selected randomly, washed with tap water, diced into approximately $0.5 \mathrm{~cm}$ cubes, freeze-dried, and ground by food processor into flour. Prepared flour was stored at $-80^{\circ} \mathrm{C}$ until use. For preparation of anthocyanin extract, $1 \mathrm{~g}$ of flour was extracted with $8 \mathrm{ml}$ of acidified $\mathrm{MeOH}(1 \mathrm{~N} \mathrm{HCL}, 85: 15$, v/v) to obtain a sample to solvent ratio of 1:8. The flour/solvent mixture was stirred at room temperature on a magnetic stirrer for $12 \mathrm{hrs}$, centrifuged at 1,800 rpm for $30 \mathrm{~min}$ and the supernatant was filtered through a Whatman \#1 syringe filter.

\subsection{General nutrient composition analysis}

General nutrient composition for each sweet potato was analyzed according to the official AOAC methods [15] for dry matter (\#930.15), crude fat (\#920.39), crude protein (\#990.03), ash (\#942.05), starch (\#920.40), and minerals (\#968.08), respectively.

\subsection{Dietary fiber content}


Total dietary fiber (TDF), insoluble dietary fiber (IDF), and soluble dietary fiber (SDF) of each sweet potato variety in this study were analyzed according to the official AOAC methods [16, 17].

\subsection{Anthocyanin identification and quantification by HPLC-MS/ESI}

The identification and quantification of anthocyanins in the sweet potato extracts were conducted by HPLC-ESI/MS/MS according to published methods $[18,19]$. Briefly, analysis was carried out on an Esquire 3000+ electrospray ion-trap mass spectrometer (Bruker Daltonics, GmH, Billerica, MA, USA) connected to an Agilent 1100 series HPLC system (Agilent Waldbronn, Germany). Reverse phase liquid chromatography was performed with a Gemini C18 stationary phase column $(2.0 \mathrm{~mm} \times 150 \mathrm{~mm}$ i.d., $3 \mu \mathrm{m}, 110 \AA)$ at $25{ }^{\circ} \mathrm{C}$. The mobile phase A consisted of $1 \%$ formic acid in double deionized water, and the mobile phase B consisted of 90:10 mixture of acetonitrile and $1 \%$ formic acid. At a flow rate of $0.2 \mathrm{~mL} / \mathrm{min}$, the gradient of solvent $\mathrm{B}$ at $2 \%$ was run to $20 \%$ in $15 \mathrm{~min}$, and then to $95 \%$ in $25 \mathrm{~min}$, and $98 \%$ in $26 \mathrm{~min}$. HPLC peaks were detected by UV/VIS at $520 \mathrm{~nm}$. The extracted samples were spiked with $5 \mu \mathrm{M}$ of peonidin3glucoside (P3G) as an internal standard. Quantification was calculated by using the integrated peak area based upon a standard curve of $\mathrm{P} 3 \mathrm{G}$ at $0-500 \mu \mathrm{M}$ and expressed as $\mathrm{P} 3 \mathrm{G}$ equivalent (P3GE).

HPLC peaks were identified based upon the published retention time and spectral data. Each peak separated by HPLC was further identified by ESI/MS/MS in positive ionization mode between 100 to $1200 \mathrm{~m} / \mathrm{z}$. Anthocyanin identification was performed based upon primary molecular weight isolation and secondary fragment confirmation of the aglycone $\mathrm{m} / \mathrm{z}$ according 
to the published database $[18,19]$. MS/ESI data were controlled and processed with Data analysis 3.3 software (Bruker Daltonics, GmbH, Billerica, MA, USA).

\subsection{Total phenolic content assay}

Total phenolics in each sweet potato extract were measured by Folin-Ciocalteu method [20] with a slight modification. Briefly, $10 \mu \mathrm{l}$ of extract was mixed with $600 \mu 1$ of water and $50 \mu 1$ of Folin-Ciocalteu reagent for $5 \mathrm{~min}$, and then mixed with $150 \mu \mathrm{l}$ of $20 \% \mathrm{Na}_{2} \mathrm{CO}_{3}$. It was then incubated at $23{ }^{\circ} \mathrm{C}$ for $2 \mathrm{hrs}$, followed by dilution with $190 \mu \mathrm{l}$ of water. The reaction solution was detected at $760 \mathrm{~nm}$ and the quantification was calculated using gallic acid as a standard curve and expressed as gallic acid equivalent (GAE).

\subsection{Total antioxidant capacity assay}

Total antioxidant capacity in each of the three sweet potato extracts was determined by the ferric-reducing ability of plasma (FRAP) test according to the published method [21]. Briefly, $270 \mu \mathrm{l}$ of FRAP reagent was mixed with $30 \mu \mathrm{l}$ of each extract at $37^{\circ} \mathrm{C}$. The absorbance was measured at $593 \mathrm{~nm}$. The quantification was calculated by using trolox as a standard curve and expressed as trolox equivalent (TE).

\subsection{Cell culture, cell number, and cytotoxicity assay}

Human colon cancer SW480 cells were cultured in Dulbecco's Modified Eagle medium supplemented with $10 \%$ fetal bovine serum and 1\% penicillin/streptomycin. As described in our previous publication [22], the cells were seeded at a density of $6 \times 10^{5}$ cells $/ \mathrm{mL}$ in 6 -well plates and incubated at $37^{\circ} \mathrm{C}$ in $5 \% \mathrm{CO}_{2}$ until $60-80 \%$ confluent. At this confluence, cells were treated with either P3G at $0-40 \mu \mathrm{M}$ or P40 extract at $0-40 \mu \mathrm{M}$ of P3GE doses. After 48 -hrs incubation, 
the cells were detached and stained by trypan blue. Both viable and unviable cell numbers were counted by a hemacytometer. Cytotoxicity was calculated compared with the vehicle controls.

\subsection{Cell cycle analysis}

The cell cycle analysis was done as previously described [22, 23]. Briefly, the treated cells were fixed in ethanol, centrifuged and then the pellet was re-suspended in phosphate buffer saline at $\mathrm{pH}$ 7.4, containing $20 \mathrm{~g} / \mathrm{L}$ propidium iodide and $5000 \mathrm{U} / \mathrm{L}$ of RNase (Promega, USA) at $37{ }^{\circ} \mathrm{C}$ for 30 min. DNA flow cytometry (FACSCaliber, Becton Dickinson, Newyork, NJ, USA) was performed with an excitation at $488 \mathrm{~nm}$ and an emission at $630 \mathrm{~nm}$. Results were reported as a percentage of the cells in each phase of the cell cycle.

\subsection{Animal diets}

Freeze-dried sweet potato powder was mixed into a basal diet AIN-93M to achieve a final 20\% of O' Henry, $20 \%$ of NC Japanese, or $10-30 \%$ of P40, respectively. The mixed diets were stored at $4^{\circ} \mathrm{C}$ in a dark environment until use. Based upon the nutrient composition of each sweet potato as shown in Table 2, diets were balanced to similar levels of protein, fat, total energy, and fiber (Table 1).

\subsection{Animal treatments}

Six- to seven-week-old female CF-1 mice, weighing 22.59 \pm 1.06 g, were housed 3-5 mice per cage on 12:12 h light-dark cycle under controlled conditions $\left(23 \pm 0.5^{\circ} \mathrm{C}, 60 \pm 5 \%\right.$ humidity $)$. They were given a basal AIM-93M diet and water ad libitum. After one week acclimatization, mice were i.p. injected with AOM at $10 \mathrm{mg} / \mathrm{kg}$ body weight in a saline vehicle once per week for 2 weeks. Additionally, a negative control group of mice without AOM was fed AIM-93M diet and injected with saline only. Mice with AOM injection were then randomly assigned to 6 
groups, and fed on basal AIN-93M, 20\% O'Henry, 20\% NC Japanese, 10\% P40, 20\% P40, or $30 \%$ P40 diet, respectively, for 6 weeks. Body weight was recorded weekly. A daily food intake per cage was recorded, but an average of daily food intake per mouse was calculated and reported.

\subsection{Aberrant crypt foci analysis}

Six weeks after the final AOM injection, all mice were sacrificed by diethyl ether anesthetization and decapitation. Organ weights of liver, spleen, and kidneys were measured in order to monitor any cide-effect of dietary treatments. Colons removed from the end of cecum to the end of rectum were opened longitudinally, rinsed in PBS, and fixed in 10\% neutral buffered formalin. Fixed colon tissues were stained with $0.2 \%$ of methylene blue solution, and aberrant crypt foci (ACF) were counted under a light microscope at 40x magnification. ACF were classified into three size groups based upon the number of crypts per focus (i.e., Small: 2-3, Medium:4-5, or Large: $>5$ crypts per field) [24]. The same colon tissues were subsequently used for immunohistochemistry.

\subsection{PCNA and Caspase-3 protein expression in situ detected by Immunohistochemistry}

As described in our previous publications $[25,26]$, the frozen colon tissue was fixed in $-70^{\circ} \mathrm{C}$ absolute ethanol and rinsed with PBS before adding 10\% formaldehyde. The fixed colon tissue was sectioned and the slides were exposed to steam in the target retrieval solution (Dakocytomation, Carpinteria, CA, USA). The monoclonal antibody against either mouse proliferating cell nuclear antigen (PCNA) or caspase-3 (Santa Cruz Biotechnology, Santa Cruz, CA) was used as a primary antibody, and the secondary antibody was BioGenex QP900 SS multilink HRP kit (BioGenex, San Ramon, CA, USA). Staining was developed with 
diaminobenzidine chromogen and counterstained with Gills hematoxylin followed by dehydration in alcohol and xylene. The density of the stain for each section was scored by a pathologist. Ten to 15 sections for each colon sample were blindly graded using computer standards. The standards of staining intensity were established at 400x by grading up to 40 colon mucosal epithelial cells in 5 unit increments from 3-5 mice per group. Data were statistically analyzed and group scores with $p \leq 0.05$ were considered significantly different.

\subsection{Statistical analysis}

Data were analyzed by using SAS statistical system, version 9.2. Results were evaluated by ANOVA using a general linear model procedure followed by Tukey's studentized range test. The results are presented as means $\pm \mathrm{SD}$ and a probability at $p<0.05$ considered significant.

\section{$3 \quad$ Results}

\subsection{General nutrient composition and dietary fiber content in the sweet potatoes}

The general nutrient composition of the three sweet potato varieties tested in this study is shown in Table 2. P40 appeared to be similar to cream-fleshed O'Henry and white-fleshed purple skin NC Japanese. Starch was the predominant nutrient component, followed by protein, fat and minerals. However, the content of soluble dietary fiber in P40 was significantly higher than that of O'Henry and NC Japanese controls (Table 2).

\subsection{The contents of anthocyanins in the sweet potatoes}

As shown in Figure 2, nine anthocyanin peaks including internal standard P3G (peak \#5) were detected by HPLC in P40 anthocyanin extract. Only minor anthocyanins (peaks 3, 4, 7 and 9) were shown in the extract of NC Japanese. Nearly undetectable anthocyanin (peak 4) was found in the extract of O'Henry. 
Following HPLC separation, ESI/MS/MS data was collected by monitoring the molecular ion characteristics for each of the 9 peaks. Eight anthocyanins excluding internal standard P3G was identified in P40. Their molecular weights, names, and the corresponding fragment aglycone $\mathrm{m} / \mathrm{z}$ data are presented in Figure 2. The predominant anthocyanins are peonidin- and cyanidinglucoside and they are highly acylated with caffeic, ferulic, and/or hydroxybenzoic acids. Total anthocyanin content in P40 and NC Japanese sweet potatoes were 7.5 and $1.9 \mathrm{~g} / \mathrm{kg} \mathrm{dw}$, respectively. No detectable amount of anthocyanins was found in O’Henry (Table 2).

\subsection{Total phenolics and total antioxidant activity in the sweet potatoes}

Total phenolic and antioxidant capacity in the three sweet potato varieties tested are shown in Table 2. P40 possessed the highest phenolic content and antioxidant capacity.

\subsection{Effects of P40 anthocyanin extracts on cell growth and cytotoxicity}

As shown in Figure 3A, treatment of human colon SW480 cancer cells with P40 anthocyanin extracts at $0-40 \mu \mathrm{M}$ of P3GE for $48 \mathrm{hrs}$ resulted in a dose-dependent decrease in viable cell number when compared with the vehicle control. The inhibition of cancer cell growth by P40 anthocyanins are much stronger than that by a positive $\mathrm{P} 3 \mathrm{G}$ control at an equivalent dose, suggesting an extra-activity of the acylated anthocyanins or a possible synergistic effect among P40 anthocyanins by other phenolics and/or anthocyanin metabolites. Furthermore, viability after treatment was generally greater than $80 \%$ in the adherent cells. Cytotoxicity in the treated cells did not significantly differ from the vehicle controls with a mean of $17.3 \%$.

\subsection{Effects of P40 anthocyanin extracts on cell cycle progression}


The treatment of SW480 cells with P40 anthocyanin extract at 10-40 $\mu \mathrm{M}$ of P3GE for 48 hrs induced cell cycle arrest at G1 significantly (Figure 3B). As the percentage of cells in G1-phase increased, the percentage of cells at S-phase decreased correspondingly.

\subsection{Effects of dietary P40 on diet consumption, body weight, and organ to body weight ratio}

While AOM did not cause any significant change, both food intake and body weight in sweet potato-fed groups were significantly reduced when compared with the basal AIN-93M group (Table 3). The body weight of the mice fed $20 \%$ and $30 \%$ of P40, however, did not differ significantly from mice fed the basal diet. Furthermore, the ratios of organ to body weight were not significantly different among the dietary treatment groups.

\subsection{Effects of dietary P40 on AOM-induced ACF formation}

As shown in Table 4, AOM induced significant ACF formation in the distal portion of the colons. Total numbers of ACF, including both large and medium ACF but not small ACF, were significantly reduced in mice fed 10-30\% P40 diets. In addition, the formation of large ACF was significantly lower in the mice fed the $20 \%$ NC Japanese diet. Some insignificant ACF was found in animals injected with saline due to a false positive observation by a blind analysis.

\subsection{Effects of dietary P40 on PCNA and Caspase-3 protein expression}

The expression of PCNA as a marker of proliferation and caspase- 3 as a biomarker of apoptosis in the colon mucosal epithelia cells was detected by immunohistochemistry. Figure 4A and 4D are the representative slides for AOM-induced PCNA and caspase- 3 expression, respectively. The percentage of PCNA stained cells significantly decreased in the mice fed $30 \%$ P40 diet 
(Figure 4B and 4C), while caspase-3 staining increased in both 20\% P40 diet and NC Japanese diet groups (Figure 4E and 4F).

\section{Discussion}

Colorectal cancer, probably the cancer most relevant to dietary factors, is the third deadliest form of cancer in both men and women in the United States [27]. Development of new cancer chemopreventive agents without adverse effect has driven research interest in dietary phytochemicals for their potential nutraceutical roles. Studies have consistently shown the cancer preventative effects of berry anthocyanins on colorectal cancer [8, 10-14]. To develop a staple food containing a high content of anthocyanins, we selected a new purple-flesh sweet potato cultivar P40. When compared with cream-fleshed or white-fleshed sweet potatoes, P40 contains similar nutrient levels. However, P40 contains much higher levels of total phenolics, antioxidant capacity, and anthocyanins.

By using HPLC- ESI/MS/MS, a total of eight anthocyanins have been identified and quantified in P40, which contribute to the total anthocyanin content of $7.5 \mathrm{~g} / \mathrm{kg} \mathrm{dw}$. It appears that P40 contains the highest level of anthocyanins compared to other purple-fleshed sweet potatoes that are reported to range between 2 and $6 \mathrm{~g} / \mathrm{kg} \mathrm{dw}[28,29]$. The predominant anthocyanin aglycones, i.e., anthocyanidins, in P40 are peonidin and cyanidin. In contrast to berry anthocyanins, sweet potato anthocyanins are generally acylated by caffeic, ferulic, and/or hydroxybenzoic acids, which is in agreement with published reports [30, 31]. In addition, P40 contains much higher levels of soluble dietary fiber than the sweet potato controls. Soluble dietary fiber in sweet potatoes is mostly composed of pectin that has been linked to colorectal cancer prevention in vivo through alleviating intestinal inflammation-associated symptoms. 
Dietary fiber goes through the process of fermentation by microbial activities in gut where produces short chain fatty acids such as butyrate. Studies showed that short chain fatty acids from fermented dietary fiber had strong anti-colorectal properties [32, 33].

To test potential anti-cancer activity, we evaluated the effects of P40 anthocyanin extracts on the growth of human colon SW480 cancer cells. A dose-dependent inhibition in cellular growth was found. It is interesting that the inhibitory effect by P40 anthocyanin extract is superior to that produced by a positive $\mathrm{P} 3 \mathrm{G}$ treatment at an equivalent concentration, suggesting that the acylated anthocyanins in P40 may be more active, or some other phytochemicals, such as soluble fiber and phenolic acids in P40, may interact synergistically. To determine the cellular mechanisms of growth inhibition of P40 anthocyanin extract on colon cancer cells, we investigated cell viability and cell cycle progression. While no significant cytotoxicity was found between treatment groups, the cells treated with P40 anthocyanin extract showed a blockage at the G1 phase of the cell cycle progression. These findings indicate that P40 anthocyanin extract inhibits cancer cell growth by inducing cell cycle arrest rather than through a cytotoxic effect.

Furthermore, the effects of dietary P40 on AOM-induced ACF formation in mouse colons were assessed. AOM is a classic carcinogen that initiates colorectal tumor development in animal models [34]. AOM-induced ACF in the colons are morphologically altered crypts, alone or in clusters, extensively identified as the earliest putative premalignant precursors to animal or human colorectal cancer $[35,36]$. We demonstrated that $10-30 \%$ of dietary P40 effectively inhibited ACF formation, specifically for both middle and large sizes of ACF. It was also found that $20 \%$ of dietary NC Japanese suppressed the large size of ACF formation only, which is probably due to carotenoids that usually exist in yellow- or white-fleshed purple skin sweet 
potatoes [37]. Subsequently, we investigated the plausible mechanisms by detecting protein expressions of PCNA and caspase-3 in the murine colon tissues. Although we did not detect specific cell cyclins to connect the changes in cell cycle arrest observed in cell culture, both biomarkers of PCNA and caspase-3 may be more direct and informative as the endpoints of a cancer preventive mechanism in vivo. PCNA is a well-known cellular proliferative marker [38], while caspase-3 is a biomarker of apoptosis induction in response to variety of apoptotic signals [39]. A significant decrease of PCNA in the colon mucosal epithelial cells was observed in the $30 \%$ P40-fed group. Although we did not detect apoptosis levels in vivo, an increase of caspase3 expression was observed in $20 \%$ P 40 -fed group only. We do not find a dose-dependent inhibition of proliferative marker or induction of apoptotic marker. We may need to include more biomarkers in response to actual changes in vivo. For example, caspase-3 is an indicator of apoptosis induction rather than apoptosis level. In addition, it may be related to a high variation of protein expression in vivo and/or the semi-quantitative method of the immunohistochemistry used. Further studies evaluating the association between dietary P40 and anthocyanin-related cancer preventive mechanisms in vivo seem warranted.

In conclusion, we developed an anthocyanin-enriched purple sweet potato P40 that contained a high level of dietary soluble fiber, total phenolics, antioxidant capacity, and anthocyanins. We demonstrated the anticancer activity of P40 in both in vitro cell culture and in vivo animal model. Treatment of human colon SW480 cancer cells with P40 anthocyanin extract resulted in a dose-dependent inhibition of cell number due to cytostatic but not cytotoxic mechanism. Dietary P40 at 10-30\% significantly inhibited AOM-induced ACF formation in the colons of CF-1 mice by inducing, at least in part, anti-proliferation and apoptosis. These findings 
suggest that the new purple-fleshed sweet potato clone P40 has positive colorectal cancer preventive benefits without toxicity in our studies, suggesting a potential for dietary use in at risk populations.

This study was supported in part by a USDA Cooperative Project KS410-0214022 from the Agricultural Experiment Station, Kansas State University (Contribution \#12-004-J from the Kansas Agricultural Experiment Station). Dr. Soyoung Lim was supported by a graduate student summer stipend from the Terry Johnson Center for Basic Cancer Research, Kansas State University. These data have been presented, in part, at the Experimental Biology 2011 and 2012, supported in part by NIH K-INBRE P20RR016475 via University of Kansas Medical Center Research Institute.

The authors have declared no conflict of interest. 


\section{$5 \quad$ References}

[1] Bovell-Benjamin, A. C., Sweet potato: a review of its past, present, and future role in human nutrition. Adv. Food Nutr. Res. 2007, 52, 1-59.

[2] Low, J. W., Arimond, M., Osman, N., Cunguara, B. et al., A food-based approach introducing white-fleshed purple skin sweet potatoes increased vitamin A intake and serum retinol concentrations in young children in rural Mozambique. J. Nutr. 2007, 137, 13201327.

[3] Hotz, C., Loechl, C., Lubowa, A., Tumwine, J.K., et al., Introduction of beta-carotene-rich orange sweet potato in rural Uganda resulted in increased vitamin A intakes among children and women and improved vitamin A status among children. J. Nutr. 2012, 142, 1871-1880.

[4] Mazza, G., Miniati, E., Anthocyanins in fruits, vegetables, and grains. CRC press, Boca Raton 1993.

[5] Steed, L. E., Truong, V. D., Anthocyanin content, antioxidant activity, and selected physical properties of flowable purple-fleshed sweet potato purees. J. Food. Sci. 2008, 73, S215S221.

[6] McKay, D. L., Blumberg, J. B., Cranberries (Vaccinium macrocarpon) and cardiovascular disease risk factors. Nutr. Rev. 2007, 65, 490-502.

[7] Ghosh, D., Konishi, T., Anthocyanins and anthocyanin-rich extracts: role in diabetes and eye function. Asia Pac. J. Clin. Nutr. 2007, 16, 200-208.

[8] Wang, L. S., Stoner, G. D., Anthocyanins and their role in cancer prevention. Cancer Lett. 2008, 269, 281-290. 
[9] Joseph, J. A., Denisova, N. A., Arendash, G., Gordon, M. et al., Blueberry supplementation enhances signaling and prevents behavioral deficits in an Alzheimer disease model. Nutr. Neurosci. 2003, 6, 153-162.

[10] Harris, G. K., Gupta, A., Nines, R. G., Kresty, L. A. et al., Effects of lyophilized black raspberries on azoxymethane-induced colon cancer and 8-hydroxy-2'-deoxyguanosine levels in the Fischer 344 rat. Nutr. Cancer. 2001, 40, 125-133.

[11] Lala, G., Malik, M., Zhao, C., He, J., et al., Anthocyanin-rich extracts inhibit multiple biomarkers of colon cancer in rats. Nutr Cancer. 2006, 54, 84-93.

[12] Shin, D. Y., Lee, W. S., Lu, J. N., Kang, M. H. et al., Induction of apoptosis in human colon cancer HCT-116 cells by anthocyanins through suppression of Akt and activation of p38MAPK. Int. J. Oncol. 2009, 35, 1499-1504.

[13] Renis, M., Calandra, L., Scifo, C., Tomasello, B. et al., Response of cell cycle/stress-related protein expression and DNA damage upon treatment of $\mathrm{CaCo} 2$ cells with anthocyanins. $\mathrm{Br}$. J. Nutr. 2008, 100, 27-35.

[14] Yun, J. M., Afaq, F., Khan, N., Mukhtar, H., Delphinidin, an anthocyanidin in pigmented fruits and vegetables, induces apoptosis and cell cycle arrest in human colon cancer HCT116 cells. Mol. Carcinog. 2009, 48, 260-270.

[15] Horwitz, W., Official Methods of Analysis of AOAC International 17th edition AOAC International, Maryland 2000.

[16] Lee, S. C., Prosky, L., DeVries, J. W., Determination of total, soluble, and insoluble, dietary fiber in foods - enzymaticgravimetric method, MES-TRIS buffer: Collaborative study. $J$. Assoc. Off. Anal. Chem. 1992, 75, 395-416. 
[17] Prosky, L., Asp, N. G., Schweizer, T. F., DeVries, J. W., Furda, I., Determination of insoluble and soluble dietary fiber in foods and food products: Collaborative study. J. Assoc. Off. Anal. Chem. 1992, 75, 360-367.

[18] Chandra, A., Rana, J., Li, Y., Separation, identification, quantification, and method validation of anthocyanins in botanical supplement raw materials by HPLC and HPLC-MS. J. Agric. Food Chem. 2001, 49, 3515-3521.

[19] Tian, Q., Konczak, I., Schwartz, S. J., Probing anthocyanin profiles in purple sweet potato cell line (Ipomoea batatas L. Cv. Ayamurasaki) by high-performance liquid chromatography and electrospray ionization tandem mass spectrometry. J. Agric. Food Chem. 2005, 53, 6503-6509.

[20] Singleton, V. L., Rossi, J. A., Colorimetry of total phenolics with phosphomolybdicphosphotungstic acid reagents. Am. J. Enol. Vitic. 1965, 16, 144-158.

[21] Benzie, I. F., Strain, J. J., The ferric reducing ability of plasma (FRAP) as a measure of "antioxidant power": the FRAP assay. Anal. Biochem. 1996, 239, 70-76.

[22] Ayella, A., Lim, S., Jiang, Y., Iwamoto, T., et al., Cytostatic inhibition of cancer cell growth by lignan secoisolariciresinol diglucoside. Nutr. Res. 2010, 30, 762-769.

[23] Qu, H., Madl, R., Takemoto, D., Baybutt, R., Wang, W., Lignans are involved in the antitumor activity of wheat bran in colon cancer SW480 cells. J. Nutr. 2005, 135, 598-602.

[24] Magnuson, B. A., South, E. H., Exon, J. H., Dashwood, R. H. et al., Increased susceptibility of adult rats to azoxymethane-induced aberrant crypt foci. Cancer Lett. 2000, 161, 185-193. 
[25] Xie, L., Jiang, Y., Ouyang, P., Chen, J. et al., Effects of dietary calorie restriction or exercise on the PI3K and Ras signaling pathways in the skin of mice. J. Biol. Chem. 2007, 282, 28025-28035.

[26] Ouyang, P., Yu, J., Doan, H.M., Xie, L., et al., Effects of exercise on phospholipid profile in the skin of mice. Cancer Prev. Res. 2010, 3, 466-477.

[27] Jemal, A., Siegel, R., Xu, J., Ward, E., Cancer statistics, 2010. CA Cancer J. Clin. 2010, 60, 277-300.

[28] Kaspar, K.L., Park, J.S., Brown, C.R., Mathison, B.D., et al., Pigmented Potato Consumption Alters Oxidative Stress and Inflammatory Damage in Men J. Nutr. 2011, 141, $108-111$.

[29] Zhu, F., Cai, Y.Z., Yang, X., Ke, J., Corke, H., Anthocyanins, hydroxycinnamic acid derivatives, and antioxidant activity in roots of different chinese purple-fleshed sweet potato genotypes. J. Agric. Food Chem. 2010, 58, 7588-7596.

[30] Islam, M. S., Yoshimoto, M., Terahara, N., Yamakawa, O., Anthocyanin compositions in sweet potato (Ipomoea batatas L.) leaves. Biosci. Biotechnol. Biochem. 2002, 66, 24832486.

[31] Terahara, N., Konczak, I., Ono, H., Yoshimoto, M., Yamakawa, O., Characterization of Acylated Anthocyanins in Callus Induced From Storage Root of Purple-Fleshed Sweet potato, Ipomoea batatas L. J. Biomed. Biotechnol. 2004, 2004, 279-286.

[32] Mei, X., Mu, T. H., Han, J. J., Composition and physicochemical properties of dietary fiber extracted from residues of 10 varieties of sweet potato by a sieving method. J. Agric. Food Chem. 2010, 58, 7305-7310. 
[33] Rose, D. J., DeMeo, M. T., Keshavarzian, A., Hamaker, B. R., Influence of dietary fiber on inflammatory bowel disease and colon cancer: importance of fermentation pattern. Nutr. Rev. 2007, 65, 51-62.

[34] Tammariello, A. E., Milner, J. A., Mouse models for unraveling the importance of diet in colon cancer prevention. J. Nutr. Biochem. 2010, 21, 77-88.

[35] Bird, R. P., Good, C. K., The significance of aberrant crypt foci in understanding the pathogenesis of colon cancer. Toxicol. Lett. 2000, 112-113, 395-402.

[36] Wargovich, M. J., Chen, C. D., Jimenez, A., Steele, V. E. et al., Aberrant crypts as a biomarker for colon cancer: evaluation of potential chemopreventive agents in the rat. Cancer Epidemiol. Biomark. Prev. 1996, 5, 355-360.

[37] Palozza, P., Sestito, R., Picci, N., Lanza, P. et al., The sensitivity to beta-carotene growthinhibitory and proapoptotic effects is regulated by caveolin-1 expression in human colon and prostate cancer cells. Carcinogenesis. 2008, 29, 2153-2161.

[38] Elias, J. M., Cell proliferation indexes: a biomarker in solid tumors. Biotech Histochem. 1997, 72, 78-85.

[39] Mazumder, S., Plesca, D., Almasan, A., Caspase-3 activation is a critical determinant of genotoxic stress-induced apoptosis. Methods Mol. Biol. 2008, 414, 13-21. 
Table 1. Composition of diets containing various sweet potatoes $(\mathrm{g} / \mathrm{kg}$ diet $)$

\begin{tabular}{|c|c|c|c|c|c|c|}
\hline & AIN-93M & $\begin{array}{l}20 \% \\
\text { O'Henry* }\end{array}$ & $\begin{array}{l}20 \% \text { NC } \\
\text { Japanese } €\end{array}$ & $\begin{array}{l}10 \% \\
\text { P40 } \ell\end{array}$ & $\begin{array}{l}20 \% \\
\mathbf{P} 40 \\
\end{array}$ & $\begin{array}{l}30 \% \\
\mathbf{P 4 0} \\
\end{array}$ \\
\hline $\begin{array}{l}\text { Freeze-dried sweet } \\
\text { potato }\end{array}$ & $\mathbf{0}$ & 200 & 200 & 100 & 200 & 300 \\
\hline Casein & 140 & 123 & 126 & 135 & 130 & 125 \\
\hline L-cystine & 1.8 & 1.8 & 1.8 & 1.8 & 1.8 & 1.8 \\
\hline Corn starch & 466 & 367 & 356 & 416 & 367 & 318 \\
\hline Maltodextrin & 155 & 81 & 86 & 113 & 72 & 30 \\
\hline Sucrose & 100 & 100 & 100 & 100 & 100 & 100 \\
\hline Soybean Oil & 40 & 38 & 39 & 39 & 39 & 38 \\
\hline Cellulose & 50 & 42 & 44 & 47 & 43 & 40 \\
\hline AIN-93M mineral mix & 35 & 35 & 35 & 35 & 35 & 35 \\
\hline AIN-93M vitamin mix & 10 & 10 & 10 & 10 & 10 & 10 \\
\hline Choline Bitartrate & 2.5 & 2.5 & 2.5 & 2.5 & 2.5 & 2.5 \\
\hline TBHQ, antioxidant & 0.008 & 0.008 & 0.008 & 0.008 & 0.008 & 0.008 \\
\hline
\end{tabular}

* Each gram of O'Henry powder contains $86 \mathrm{mg}$ of protein, $8 \mathrm{mg}$ of fat, $495 \mathrm{mg}$ of starch, and 40 mg of fiber

$€$ Each gram of NC Japanese powder contains $68 \mathrm{mg}$ of protein, $6 \mathrm{mg}$ of fat, $548 \mathrm{mg}$ of starch, and $30 \mathrm{mg}$ of fiber

$\ell$ Each gram of P40 powder contains $51 \mathrm{mg}$ of protein, $6 \mathrm{mg}$ of fat, $493 \mathrm{mg}$ of starch, and $33 \mathrm{mg}$ of fiber 
Table 2. Composition of general nutrients and bioactive compounds in cream-fleshed O'Henry, white-fleshed purple skin NC Japanese and purple-fleshed P40 sweet potatoes

\begin{tabular}{|c|c|c|c|}
\hline & O’Henry & NC Japanese & $\mathrm{P} 40$ \\
\hline Dry matter $(\%)^{*}$ & 19.9 & 32.0 & 29.0 \\
\hline Protein $(\%)^{* \neq}$ & 1.7 & 2.2 & 1.5 \\
\hline Fat $(\%)^{*}$ & 0.2 & 0.2 & 0.2 \\
\hline $\operatorname{Ash}(\%)^{*}$ & 1.1 & 1.4 & 1.3 \\
\hline $\operatorname{Starch}(\%)^{*}$ & 9.8 & 17.5 & 14.4 \\
\hline \multicolumn{4}{|l|}{ Dietary fiber $(\%)^{\S}$} \\
\hline IDF & $9.3 \pm 0.2$ & $8.4 \pm 1.9$ & $8.4 \pm 1.3$ \\
\hline SDF & $4.5 \pm 1.0^{\mathrm{b}}$ & $3.6 \pm 1.7^{\mathrm{b}}$ & $7.4 \pm 1.4^{\mathrm{a}}$ \\
\hline TDF & $13.8 \pm 0.9$ & $12.0 \pm 0.5$ & $15.8 \pm 0.5$ \\
\hline $\begin{array}{l}\text { Anthocyanins content } \\
\text { (mg P3GE/g dw) }\end{array}$ & ND & $1.9 \pm 0.0^{b}$ & $7.5 \pm 0.4^{\mathrm{a}}$ \\
\hline $\begin{array}{l}\text { Total phenolic content } \\
\quad(\mathrm{mg} \mathrm{GAE} / \mathrm{g} \mathrm{dw})\end{array}$ & $16.1 \pm 0.5^{\mathrm{c}}$ & $25.6 \pm 1.3^{\mathrm{b}}$ & $74.6 \pm 0.29^{\mathrm{a}}$ \\
\hline$\frac{\text { Antioxidant capacity }}{(\mathrm{mg} \mathrm{TE} / \mathrm{g} \mathrm{dw})}$ & $\underline{49.1 \pm 11.8^{b}}$ & $\underline{47.9 \pm 1.1^{\mathrm{b}}}$ & $\underline{84.4 \pm 1.4^{\mathrm{a}}}$ \\
\hline
\end{tabular}

* Data are reported on a $100 \%$ fresh weight basis;

‡ Protein is calculated using a 6.25 conversion factor;

$\S$ Data are reported as percent of dry matter and expressed as means $\pm \mathrm{SD}, \mathrm{n}=4$. Means in a row without a common letter differ, $p<0.05$. IDF, insoluble dietary fiber; SDF, soluble dietary fiber; TDF, total dietary fiber.

$¥$ Values are means $\pm \mathrm{SD}, \mathrm{n}=4$. Means in a row without a common letter differ, $p<0.05$. ND, non-detected; dw, dry weight; P3GE, peonidin 3-glucoside equivalent; GAE, gallic acid equivalent; TE, trolox equivalent. 
Table 3. Effects of dietary P40 on food intake, body weight, and organ to body weight ratio*

\begin{tabular}{ccccccc}
\hline Diet groups & AOM & Food intake $^{\#}$ & Final body & \multicolumn{3}{c}{ Organ to body weight ratio (\%) } \\
\cline { 5 - 7 } & injection & $(\mathrm{g} /$ day $/$ mouse $)$ & weight $(\mathrm{g})$ & Liver & Spleen & Kidneys \\
\hline AIN-93M & + & $9.3 \pm 1.3^{\mathrm{a}}$ & $34.0 \pm 3.2^{\mathrm{a}}$ & $4.8 \pm 0.5$ & $0.4 \pm 0.2$ & $1.1 \pm 0.2$ \\
AIN-93M & - & $9.6 \pm 1.0^{\mathrm{a}}$ & $38.3 \pm 4.3^{\mathrm{a}}$ & $4.1 \pm 0.6$ & $0.3 \pm 0.1$ & $1.1 \pm 0.1$ \\
$20 \%$ O'Henry & + & $6.3 \pm 0.8^{\mathrm{b}}$ & $28.1 \pm 2.4^{\mathrm{c}}$ & $4.9 \pm 0.5$ & $0.5 \pm 0.2$ & $1.1 \pm 0.1$ \\
$20 \%$ NCJapanese & + & $5.7 \pm 0.8^{\mathrm{b}}$ & $29.1 \pm 3.2^{\mathrm{c}}$ & $4.9 \pm 0.6$ & $0.5 \pm 0.2$ & $1.2 \pm 0.4$ \\
$10 \%$ P40 & + & $5.8 \pm 0.5^{\mathrm{b}}$ & $31.3 \pm 3.7^{\mathrm{b}}$ & $4.6 \pm 0.5$ & $0.5 \pm 0.2$ & $1.2 \pm 0.3$ \\
$20 \% \mathrm{P} 40$ & + & $6.1 \pm 1.2^{\mathrm{b}}$ & $32.9 \pm 3.2^{\mathrm{a}}$ & $3.9 \pm 0.4$ & $0.3 \pm 0.0$ & $1.1 \pm 0.2$ \\
$30 \%$ P40 & + & $6.3 \pm 1.0^{\mathrm{b}}$ & $32.9 \pm 3.5^{\mathrm{a}}$ & $4.2 \pm 0.7$ & $0.5 \pm 0.2$ & $1.2 \pm 0.4$ \\
\hline
\end{tabular}

* Data are means $\pm \mathrm{SD}, \mathrm{n}=5-7$. Means in a column without a common letter differ, $\mathrm{p}<0.05$.

${ }^{\#}$ Mean food intake in the final week of experimental period is presented. 
Table 4. Effects of dietary P40 on Azoxymethane (AOM)-induced aberrant crypt foci (ACF) multiplicity in the colons of CF-1 mice ${ }^{¥}$

\begin{tabular}{cccccc}
\hline Diet groups & $\begin{array}{c}\text { AOM } \\
\text { injection }\end{array}$ & $\begin{array}{c}\text { Total } \\
\text { ACF/colon }\end{array}$ & Small (2-3) & $\begin{array}{c}\text { Medium } \\
(4-5)\end{array}$ & Large $(\geq 5)$ \\
\hline AIN-93M & + & $53.4 \pm 11.4$ & $22.0 \pm 7.1$ & $18.0 \pm 3.2$ & $13.4 \pm 3.4$ \\
AIN-93M & - & $3.0 \pm 1.9$ & $1.0 \pm 1.0$ & $1.4 \pm 0.9$ & $0.6 \pm 0.6$ \\
$20 \%$ O'Henry & + & $41.2 \pm 1.3$ & $17.3 \pm 2.2$ & $14.7 \pm 1.8$ & $9.2 \pm 0.8$ \\
$20 \%$ NC Japanese & + & $35.8 \pm 13.6$ & $17.2 \pm 6.6$ & $12.2 \pm 4.8$ & $6.5 \pm 2.7^{* *}$ \\
$10 \%$ P40 & + & $32.6 \pm 10.7 *$ & $15.7 \pm 5.9$ & $10.7 \pm 3.8^{*}$ & $6.1 \pm 2.8^{* *}$ \\
20\% P40 & + & $26.7 \pm 12.9^{* *}$ & $13.1 \pm 7.5$ & $8.7 \pm 3.2^{* *}$ & $4.9 \pm 2.9^{* *}$ \\
$30 \%$ P40 & + & $22.0 \pm 13.1^{* *}$ & $12.4 \pm 3.1$ & $9.4 \pm 5.7^{*}$ & $4.6 \pm 1.3^{* *}$ \\
\hline
\end{tabular}

$¥$ Data are means $\pm \mathrm{SD}, \mathrm{n}=5-7 .{ }^{*} p<0.05$ or $* * p<0.01$ versus the basal AIN-93M diet with AOM injection control. 


\section{Figure Legends:}

Figure 1. Purple-fleshed sweet potato P40 versus cream-fleshed O'Henry and white-fleshed purple skin NC Japanese sweet potatoes grown at the John C. Pair Horticulture Research Center, Wichita, Kansas.

Figure 2. Representative HPLC chromatograms and MS data of anthocyanins detected in each of three sweet potato varities. Peonidin 3-glucoside was used as an internal standard (peak \#5). Each anthocyanin peak is identified by ESI/MS/MS. The primary molecular weight, anthocyanin names, and $\mathrm{m} / \mathrm{z}$ of the secondary fragment confirmation of the corresponded anthocyanin aglycones are listed in the inserted table.

Figure 3. Effects of P40 anthocyanin extract on cell growth and cell cycle progression in human colon SW480 cancer cells. (A) Treatment of cells with P40 anthocyanin extract at 10-40 $\mu \mathrm{M}$ of peonidin-3-glucoside equivalence for $48 \mathrm{hrs}(\mathbf{m})$ versus the positive peonidin 3-glucoside control ( $\square)$. Data are means $\pm \mathrm{SD}, \mathrm{n}=3$, Means within a treatment without a common letter are significantly different, $p<0.05$. (B) Cells co-cultured with P40 anthocyanin extract at 10-40 $\mu \mathrm{M}$ of peonidin-3-glucoside equivalence for $48 \mathrm{hrs}$ were analyzed by flow cytometry as described in the Materials and Methods. Data are means $\pm \mathrm{SD}, \mathrm{n}=3, * * p<0.01$ versus the vehicle control.

Figure 4. Effects of dietary P40 on the expression of PCNA and caspase-3 in the colon mucosal epithelial cells of mice injected with AOM. The top panel shows the representative immunohistochemical PCNA staining on colon tissue of CF-1 mice fed the basal AIN-93M diet (A), 30\% of P40 diet (B), or caspase-3 staining on colon tissue of CF-1 mice fed the basal AIN93M diet (D), 20\% of P40 diet (E). The bottom panel is a quantification of the stained colon 
mucosal epithelial cells for PCNA (C) and caspase-3 (F), respectively. Data are means $\pm \mathrm{SD}, \mathrm{n}=$ $5, * \mathrm{p}<0.05$ or $* * \mathrm{p}<0.01$ versus the basal AIM-93M diet-fed mice with AOM injection. 